\title{
SOME FUNCTIONS AND CONTEXTS OF TRADITIONAL POTTERY IN NORTHERN GHANA
}

\author{
${ }^{1}$ Mr. Iddrisu Yussif, \\ ${ }^{1}$ Department of Industrial Arts, Tamale Technical University, P. O. Box 3 E/R \\ Tamale, Ghana \\ yiddrisu@tatu.edu.gh \\ $+233247985248 /+233202855355$ \\ ${ }^{2}$ Mrs.Vesta E. Adu-Gyamfi, and ${ }^{3}$ Dr.Kafui Kwesi Agyenan \\ ${ }^{2 \& 3}$ Department of Integrated Rural Art and Industry, Faculty of Art and Built Environment, \\ Kwame Nkrumah University of Science and Technology, University Post Office, Private \\ Mail Bag, Kumasi - Ghana \\ ²adugyamfivesta@yahoo.com \\ $+233208168610$ \\ 3kkagyeman@knust.edu.gh \\ $+233244991753$
}




\begin{abstract}
The aim of this paper is to identify and document some functions and contextsof traditional pottery within northern Ghana. The descriptive approach of the qualitative research methodology was employed. Interview and observation methods were employed as the data collection methods. They were used to ascertain reasons why some potteryare engaged in certain contexts andfor certainfunctions. The data was tabulated to include the traditional name of the pot, the function and the context. The data were then analyzed and the indications were that, the potters make interesting forms of traditional pottery for different purposes; and the local name given to each pot perfectly defines their functions and contexts within northern Ghana. On the flipside of the coin, the function and context of every pot can also be dictated by its end user. Base on this, the researchers were able to discover some functions and contexts of the indigenous pottery which were put into some groups. On the first hand, the researchers classified the functions into five groups of purpose. These included: domestic purposes, religious purposes, agricultural purposes, rites of passage purposes and traditional herbal medicinal purposes. On other hand, seven groups of contexts were also discovered at the time of the study. These included: courtyards, bedrooms, bathrooms, graveyards, kitchens, shrines, and hencoops as places where these pots can be found among the people of the Northern Ghana.
\end{abstract}

Keywords: Functions, Contexts, Traditional Pottery, Northern, Ghana 


\section{INTRODUCTION}

In basic Functionalist terms, if an item exists in a context it must have a reason for existing and hence it must serve some kind of function (Livesey, 2010). Prelude efforts made by researchers to define the functions and contexts of traditional pottery often involve quite a lot of concepts that seem to need widespread explanation. Since every traditional pottery produced has its moment in history - a time when it has existing context and function; and a time when the tide of social activities in their context and function flows in its favor (Crickmay, 2015). The literature on traditional pottery shows a possiblemethodof portraying and documenting the functions and contexts sufficiently, but it is neither straight to the point nor workable enough for a successful description of their functions and contexts. This is because when an indigenous pot is not carefully used in time and properly at its defined context their functions disappear. But these are things that the researchers investigated, and for which should always seek and find direct and indirect evidence as well as truth. Commonly speaking, Context and function (with reference to traditional pottery in Ghana) are everything. They shape the meaning of all traditional pottery generally. Without context, traditional pottery can't function effectively. When traditional pottery is produced and delivered in one particular context, but received in another or different context it likely leads to malfunction (Bradley, 2014). What then are the word meanings of context and function? The context of a work of art refers to the cultural constraints and expectations that surrounded and influenced the artist's creation (Tmcdanel, 2013). Quite apart from this definition, Tmcdanel (2013) made it clear that, contexts of traditional pottery usually include religious beliefs of both the artist and the larger community. the political events of the time and the artist's view of those events, the work of contemporary artists, the cultural values and conflicting perspectives of the end users. On the other side, function can be defined as the 
aim of a product and the way it operates. The function of a product is what you can do with it and what you achieve from it e.g. storing water is the function of a traditional water cooler (Ilse, Pieter, \&Prabhu, 2005). They also did mention that, to achieve a function, a product needs to be used in a prescribed way at a given geographical area. Conclusions drawn from the above definitions indicate that, traditional pottery context and function may be separate in time, but they are often equally important to the artifact. The fact is that within milliseconds and before viewers and end users has had a chance to even think about the decorative aspect of a traditional pot; already its context and function sets an atmosphere for everything that follows. Due to poor imprecise documentation regarding these contexts and function, the research sort to answer questions about some of the functions and contexts of existing traditional pottery in Northern Ghana?

\section{CONCEPTS AND METHODS}

\section{Concept}

This paper aims at identification of some functions and contextstraditional potteryin northern Ghana. This is to create worldwide awareness on the functions and contexts of pottery in northern Ghana. In addition, the study was done to contribute to the constructive documentation of these existing pottery functions and contexts in northern Ghana.

\section{Methods}

The populations of the study include pottery makers and user in selected pottery communities in the Northern Sector of Ghana. These include seven localities from six districts as presented in table 1, also including respondents' statistics. This is also supported by figure 1: a display of the map of Ghana showing the location of the sites of the study.

Due to the unpredictability of the data, the qualitative research approach was adopted.In this regard, the researcherssort to understand the functions and contexts of some traditional 
pottery in the Northern Ghana through visiting of their respective sites and recording data through personal contacts with the people. Due to the descriptive nature of the research design, the data was subjected to comparative analysis, an analysis fashioned based on researchers' previous experience in literature and field data. The dataincludephotographs of traditional pottery, participant's audio/video recordings based on interviews, direct observations, and participant-observation as the data collection methods.

With reference to Creswell (2003), it was clear to the researchers that this research was on participants' perceptions and experiences, and the way they make sense of their lives with traditional pottery. A distinguishing mark of case study research is the use of manifold data sources, an approach which also improve data reliability (Yin, 2003).

Table 1: Distribution of sample sizes made for the research work.

\begin{tabular}{|l|c|c|c|}
\hline DISTRICT & $\begin{array}{c}\text { POTTING } \\
\text { CENTRE }\end{array}$ & $\begin{array}{c}\text { NUMBER OF } \\
\text { RESPONDENTS }\end{array}$ & $\begin{array}{c}\text { NUMBER OF POTTERY } \\
\text { COLLECTED FROM EACH } \\
\text { CENTRE }\end{array}$ \\
\hline $\begin{array}{l}\text { KASINA NANKANA } \\
\text { WEST DISTRICT }\end{array}$ & SIRIGU & 15 & 8 \\
\hline PUSIGA DISTRICT & ZUBULGA & 9 & 4 \\
\cline { 2 - 4 } & PALNABA & 20 & 4 \\
\hline $\begin{array}{l}\text { KUMBUNGU } \\
\text { DISTRICT }\end{array}$ & LUGSHIGU & 11 & 8 \\
\hline $\begin{array}{l}\text { SABOBA } \\
\text { CHERIPHONI } \\
\text { DISTRICT }\end{array}$ & NAAKPILI & 15 & 4 \\
\hline LAWRA DISTRICT & TUGGO & 15 & 40 \\
\hline $\begin{array}{l}\text { TAMALE } \\
\text { METROPOLITAN }\end{array}$ & KUKUO & 15 & 4 \\
\hline \multicolumn{4}{|c|}{ Total number of sample sizes made for the research } \\
\hline 6 & 7 & 100 & 4 \\
\hline
\end{tabular}




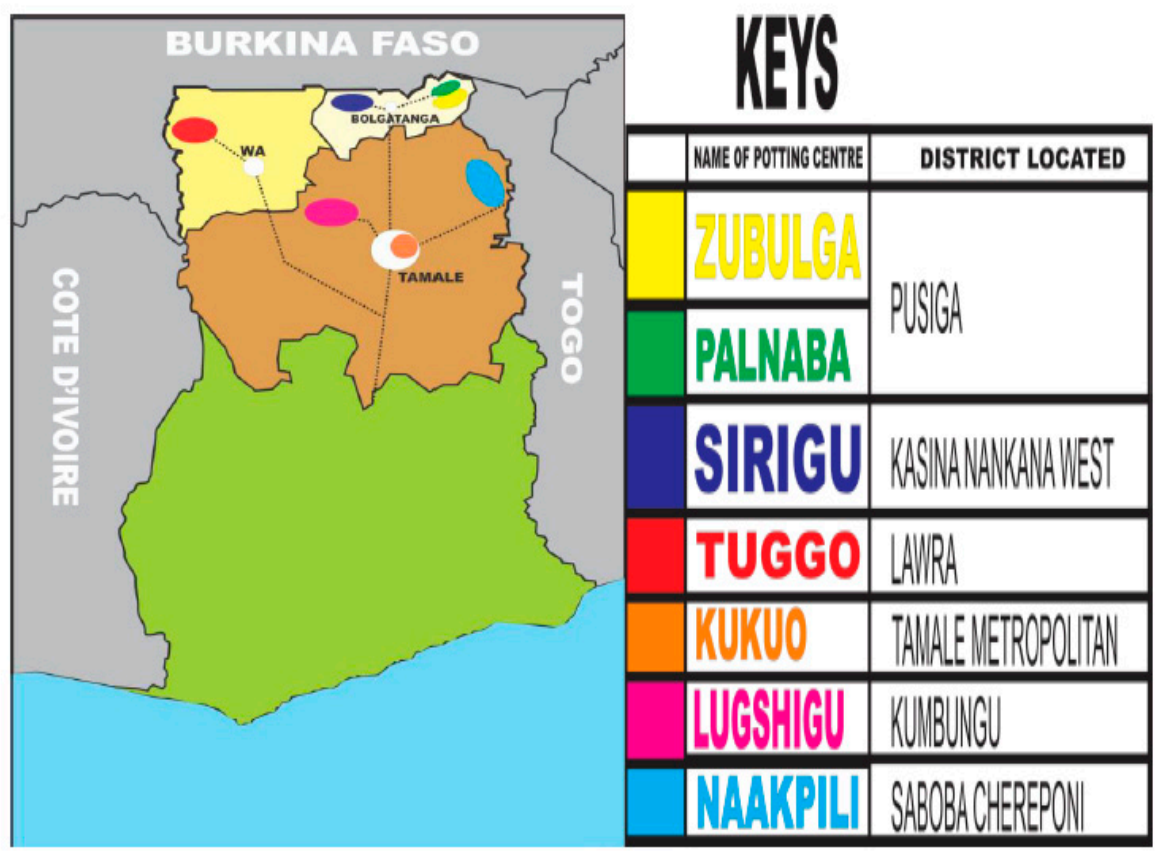

Fig. 1: Map of Ghana with selected areas in the Northern Regions

The subject and methods of the study were explained to the traditional potters and end users when they were first approached. No specific kind of information was mentioned as being of particular importance for the study, nor was any information about the study concealed from them. They were assured that the study required them to spend very little extra time, although any additional time or information that they might be willing to volunteer would be more than welcome. The observation and interviews were with no attempt to control or influence the pottery contexts and functions. Some identified traditionalpotteries were observed, one by one, as the participants were performing their regular jobs related to the pottery functions and that of their contexts. Using the purposeful sampling design,nine different types of oblivious traditional pottery were observed at each individual traditional home located among the three Northern Regions of Ghana. Sometraditional potters and pottery userswere asked to think aloud but only to the extent that such verbalization would not interfere with their pottery functions and contexts. These verbalizations were recorded and transcribed base on the data collection protocol. Identified traditional potters and pottery users in northern Ghana were observed during pottery activities base on functions and contexts. Questioning during this 
observation period was kept to the minimum in order to avoid any possible negative influence on thehumanbehavior that may affect the data. Most traditional potters and pottery users, however, initiated conservations about their specific pottery functions and contexts. Questions during such instances attempted to keep the conservation alive and were meant to be as nondirective as possible. At the end of the observation period, when the first version of the description of traditional pottery functions and contexts were drafted, the potters and pottery users were interviewed. The interviews took the form of informal conservation which was the natural thing for the potters and pottery users to do after the researchersspend a period of time with their observation guide. The researchers asked many questions to clarify issues that arose during the observation period but could not be asked then. In the interview, questions were directed to aspects of the traditional pottery functions and contexts that were not traditionally accessible bythe researchers. The recorded verbalization of the traditional potters and pottery user thought processes during the observation made, the transcribed interviews, pictures took and audio/ video recordedwere the data subject to comparative and cognitiveanalysis to arrive at the results for the study.

\section{RESULTS AND DISCUSSION}

This segment contains the various studies made by the researchers on the oblivious indigenous pottery functions and contexts in the northern part of Ghana. Clearly speaking, before the researchers could determine the functions and contexts of the indigenous pottery, the concentration of the studywas entirely based on their local names. This is simply because; the local name of an indigenous pot perfectly defines its functions and context within the locality. The tablebelow is a setup of the functions and contexts oftheindigenous pottery identified by the researchers. Generally, the table is divided into three columns; that is, the local name/location of the pot, its function and lastly its context. 
Table 2: Studies on some indigenous pottery functions and contexts in northern Ghana

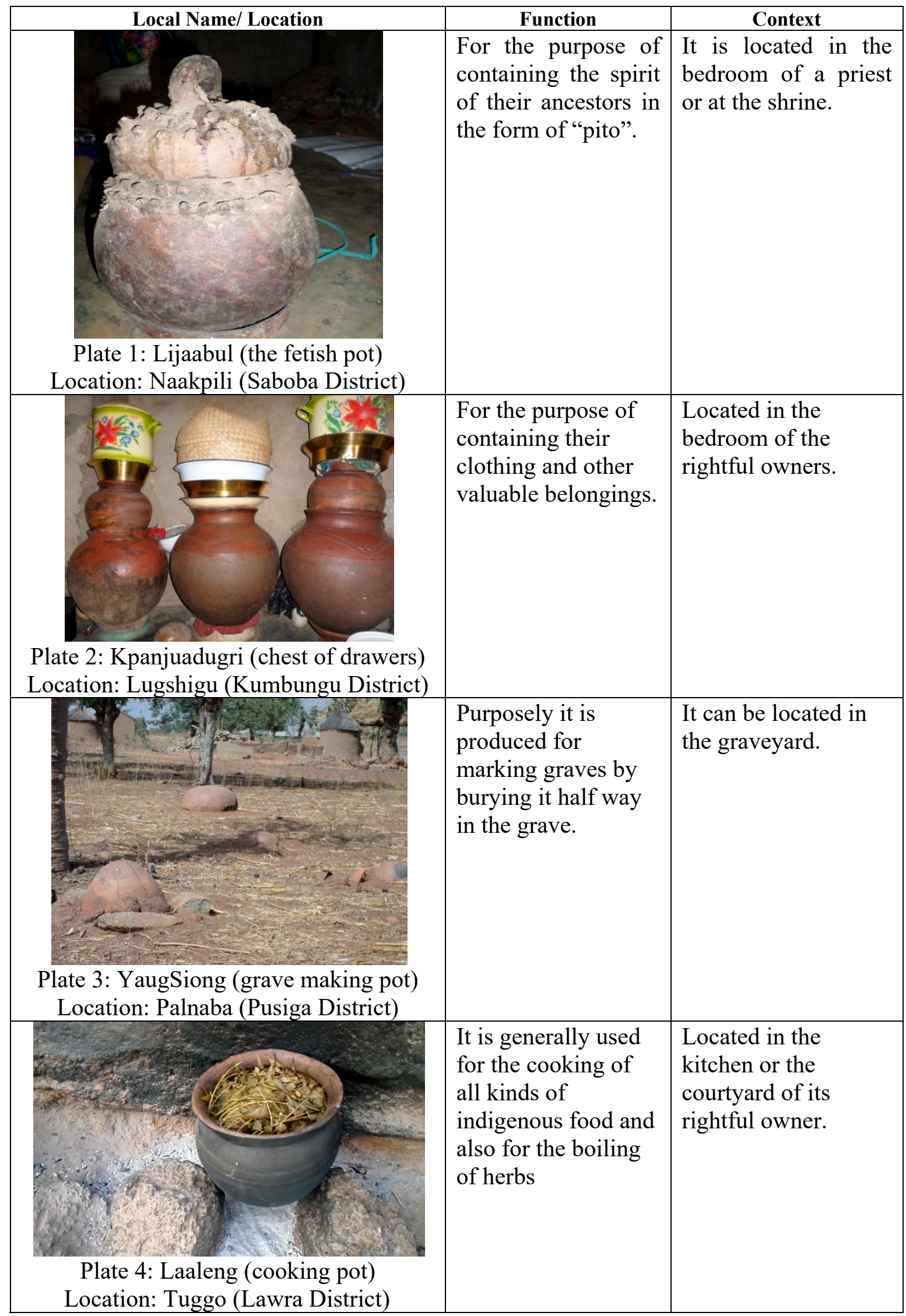




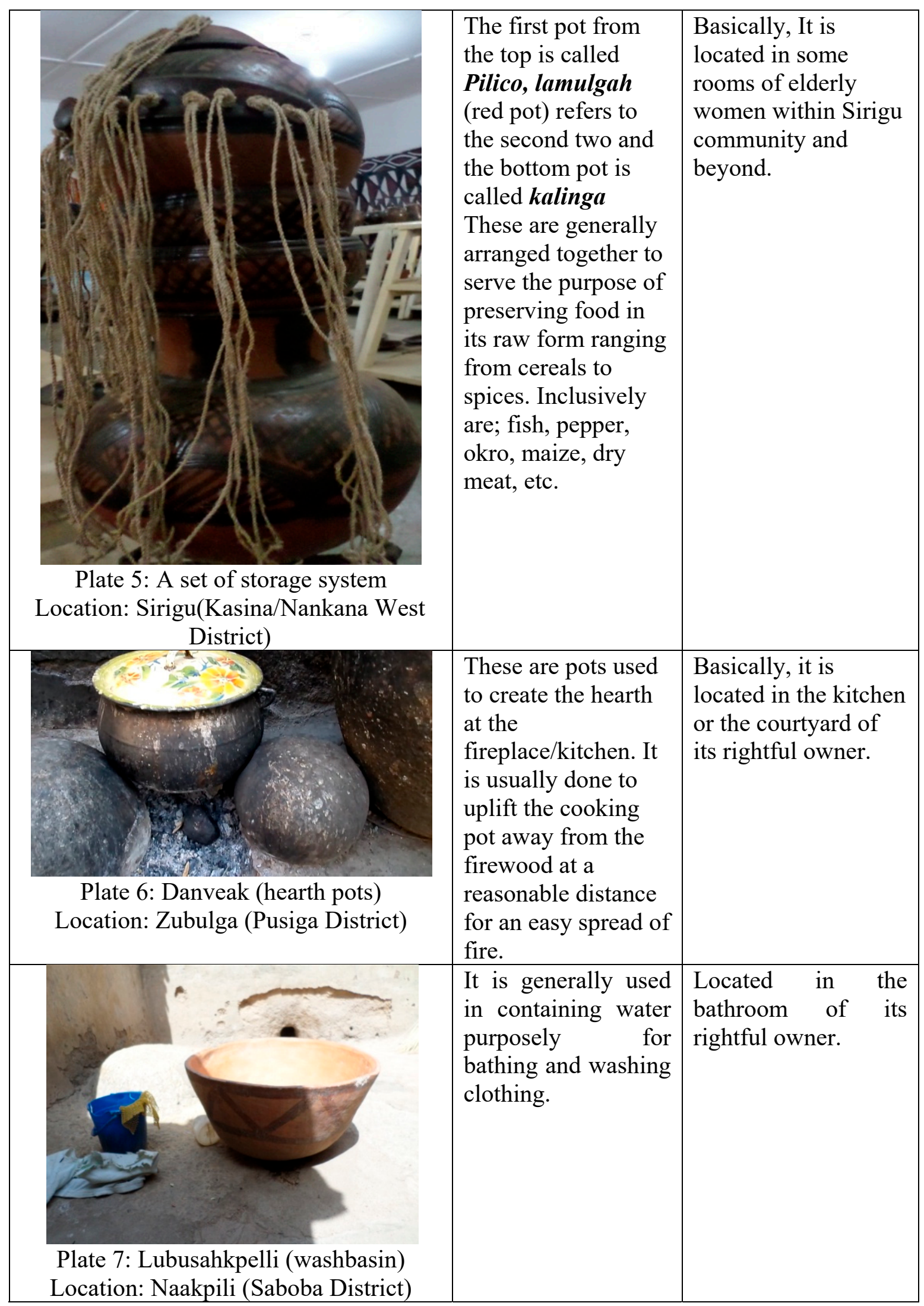




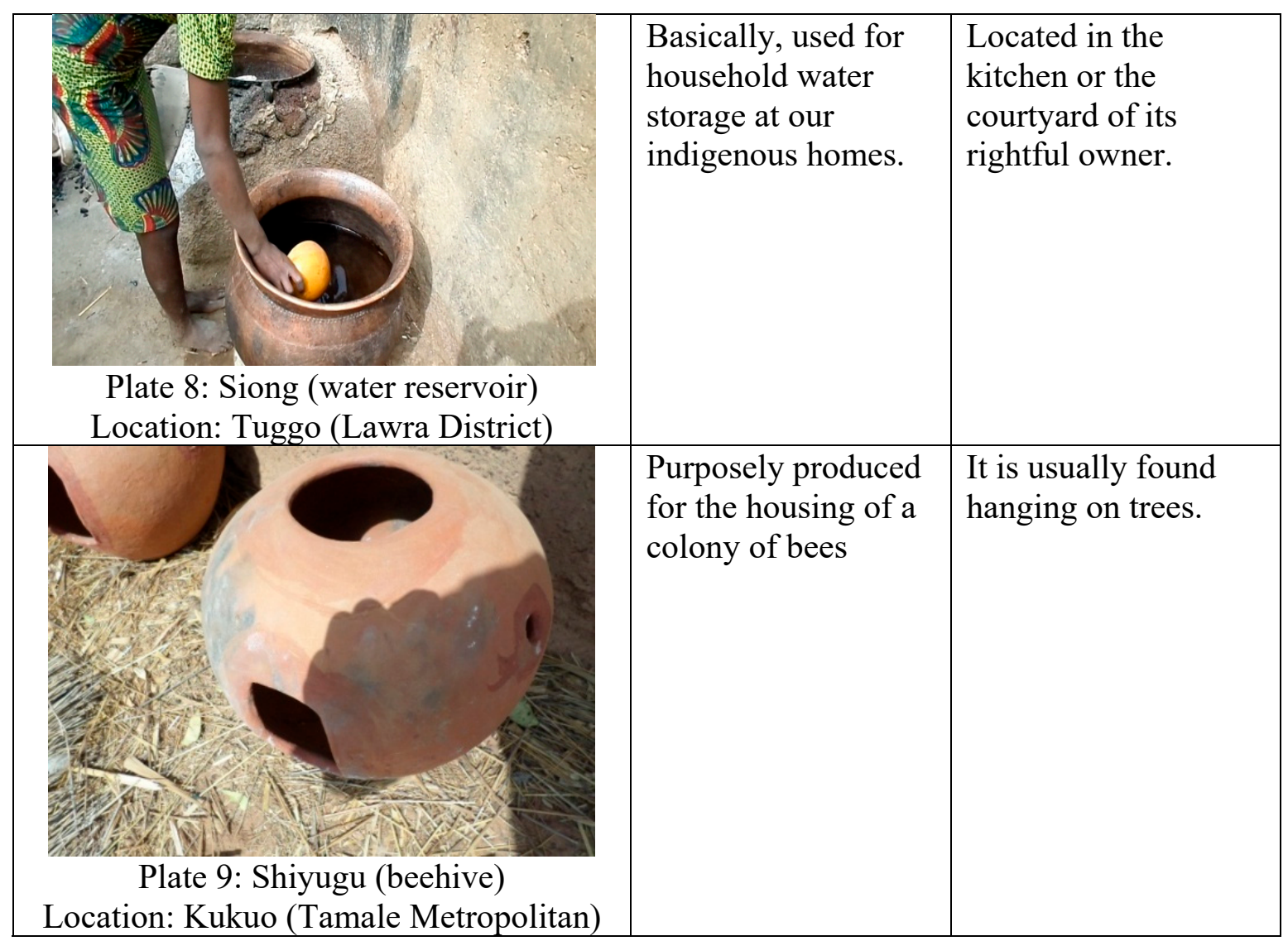

\section{CONCLUSION}

In conclusion, studies made by the researchers clearly shows that traditional pottery found in northern Ghana are generally produced from the idea of domestic functions, religious functions, and rites of passage functions. On the flip side of the coin, contexts of traditional pottery found at in northern Ghana included the courtyards, bedrooms, bathrooms, graveyards and the kitchens of their rightful owners.

\section{RECOMMENDATIONS}

The study made by the researchers show that some associated functions and contexts of traditional pottery in Northern Ghana has been grown into extinct (due to the higher demand of domestic metallic and plastic utilitarian goods). It is therefore recommended that research 
should be done on these potteries in other to understand and document their functions and contexts and how they can be brought back to life.

Even though, studies have been made on the identification of thefunctions and contexts of traditional pottery in northern Ghana, it is recommended that studies should also be made on the forming and firing techniques of traditional pottery in northern Ghana.It is also recommended that, research work should be done on the concepts associated with traditional decorative techniques on pottery in northern Ghana. Finally, the researcher recommends that, studies should be done on the influence of African aesthetics on traditional pottery in northern Ghana. 


\section{REFERENCES}

Bell, J. (2010). Doing Your Research Project: A guide for first-time researchers in education, health and social science. London: Open University Press.

Bradley, S. (2014, June 26). The Importance Of Context. Retrieved September 7, 2016, from Vanseo Design: http://vanseodesign.com/web-design/importance-context/

Crickmay, C. (2015, May 13). ART AND SOCIAL CONTEXT contextual art practice in education. Retrieved September 6, 2016, from David Harding:

http://www.davidharding.net/\%3Fpage_id\%3D22

Decorative Applied Art. (1970-1979). Retrieved June 15, 2016, from The Great Soviet Encyclopedia, 3rd Edition:

http://encyclopedia2.thefreedictionary.com/Decorative+Applied+Art

Function . (2015, September 21). Retrieved September 24, 2016, from Merriam-Webster: http://www.merriam-webster.com/dictionary/function

Livesey, C. (2010). Functionalist Theories. Retrieved September 18, 2016, from Sociology Central Crime and Deviance: www.sociology.org.uk

Rouse, M. (2005, September 3). Functions. Retrieved September 21, 2016, from Computing fundamentals glossary: http://farside.ph.utexas.edu/teaching/329/lectures/node17.html

Shepard, A. O. (1956). Ceramics for the archaeologist. Wasshington D.C: Carnegie Institution of Washington.

Tmcdanel. (2013, February 25). What is a definition of context in art terms? Retrieved September 7, 2016, from Answers:

http://www.answers.com/Q/What_is_a_definition_of_context_in_art_terms 